\title{
Taxonomic Status of a Salamander Species Allied to Hynobius naevius and a Reevaluation of Hynobius naevius yatsui Oyama, 1947 (Amphibia, Caudata)
}

\section{AUTHOR(S):}

Tominaga, Atsushi; Matsui, Masafumi

\section{CITATION:}

Tominaga, Atsushi ...[et al]. Taxonomic Status of a Salamander Species Allied to Hynobius naevius and a Reevaluation of Hynobius naevius yatsui Oyama, 1947 (Amphibia,

Caudata). Zoological Science 2008, 25(1): 107-114

\section{ISSUE DATE:}

2008-01

URL:

http://hdl.handle.net/2433/85315

RIGHT:

(c) 日本動物学会 / Zoological Society of Japan 


\title{
Taxonomic Status of a Salamander Species Allied to Hynobius naevius and a Reevaluation of Hynobius naevius yatsui Oyama, 1947 (Amphibia, Caudata)
}

\author{
Atsushi Tominaga ${ }^{\dagger}$ and Masafumi Matsui ${ }^{*}$ \\ Graduate School of Human and Environmental Studies, Kyoto University, \\ Sakyo-ku, Kyoto 606-8501, Japan
}

\begin{abstract}
A Japanese small salamander, Hynobius naevius (Temminck and Schlegel, 1838), has recently proven to include two species (larger $[A]$ and smaller [B]) that are reproductively isolated and are genetically and morphologically distinct from each other. Of these two species, Species $A$ is considered to correspond to true $\mathrm{H}$. naevius. To determine the name of Species B, we investigated five specimens stored at Kyushu University and concluded from the locality and date of collection that they represent syntypes of $\boldsymbol{H}$. n. yatsui Oyama, 1947. Results of morphological comparisons indicated that the syntypes are identical with Species B. Because this species is distinct from Hynobius naevius at the species level, subspecies $H$. $n$. yatsui is elevated to full species rank as $H$. yatsui. To avoid taxonomic confusion, we designated one male among the syntypes as the lectotype and redescribed the species.
\end{abstract}

Key words: cryptic species, western Japan, morphological comparison, redescription, nomenclature

\section{INTRODUCTION}

A Japanese small salamander, Hynobius naevius (Temminck and Schlegel, 1838), has long been considered as a single species widely occurring in western Honshu, Shikoku, and Kyushu (Sato, 1943). The species, however, has recently proven to include two distinct species - Species A (larger species=Type A of Tominaga et al. [2003], Group A of Tominaga et al. [2005a, b], Group I of Sakamoto et al. [2005], and Clades 1+2 of Tominaga et al. [2006]) and Species B (smaller species=Type B of Tominaga et al. [2003], Group B of Tominaga et al. [2005a, b], Group II of Sakamoto et al. [2005], and Clades 3+4 of Tominaga et al. [2006]) that are genetically and morphologically distinct and reproductively isolated from each other (Tominaga et al. 2003, 2005a,b; Sakamoto et al., 2005). Furthermore, comparisons of the type series of $H$. naevius with specimens of these two species revealed that Species $\mathrm{A}$, ranging from the Chugoku to northern Kyushu regions, corresponds to true $H$. naevius with its type locality in northwestern Kyushu (Tominaga and Matsui, 2007). The name of Species B has been left undetermined.

Species B, widely distributed in Chubu-Kinki, Shikoku, and Kyushu regions (Tominaga et al. 2005a, b), has long been reported to differ from true $H$. naevius from Chugoku to northern Kyushu (Sato, 1943; Oyama, 1940, 1947). Oyama (1940) listed the new name $H$. $n$. yatsui as endemic

\footnotetext{
* Corresponding author. Phone: +81-75-753-6846; Fax : +81-75-753-6846;

E-mail : fumi@zoo.zool.kyoto-u.ac.jp

† Present address: Tropical Biosphere Research Center, University of the Ryukyus, Senbaru 1, Nishihara, Okinawa 901-0213, Japan doi: $10.2108 / z$ sj.25.107
}

to Kyushu in an abstract of a meeting. Later in 1947, he again reported this subspecies with its diagnosis and the name of the type locality, Aso district, Kumamoto Prefecture, central Kyushu (Oyama, 1947). The locality Aso sensu Oyama (1947) seems to include a wide region in central Kyushu (see below), where $H$. naevius (Species A) has its southernmost range extent, while Species $B$ occurs widely except for the areas surrounding Mt. Aso (Sakamoto et al., 2005). Thus, $H$. n. yatsui more likely corresponds to Species $B$ than to $H$. naevius. However, this subspecies name has seldom been used except as a synonym of $H$. naevius (see Sato, 1943), and, therefore, the validity of this name should be taxonomically evaluated. Moreover, because a namebearing type of $H$. n. yatsui was not explicitly designated by Oyama $(1940,1947)$, the presence or absence of specimens used for description of $H$. $n$. yatsui should be confirmed.

Recently, we found specimens that were likely used for presenting $H$. $n$. yatsui by Oyama $(1940,1947)$ in the zoological collection of Kyushu University, where he worked at the time of his publications. We examined 1) whether or not features of these specimens are identical to those described for $H$. n. yatsui; 2) whether or not these specimens correspond to Species B; and 3) whether or not the name H. $n$. yatsui is valid in the light of International Code of Zoological Nomenclature (= 'Code'; ICZN, 2000). As a result, we concluded that Species B should be called $H$. yatsui. Because the original description of $H$. n. yatsui is insufficient, we provide herein a redescription of this taxon.

\section{MATERIALS AND METHODS}

We tried to locate specimens referable to Oyama's (1947) $H$. n. yatsui. We searched Oyama's collections at Kyushu University (Faculty of Agriculture) where he was working as an associate professor at the time of the description, at Kumamoto University to 
Table 1. Measurements (in $\mathrm{mm}$ ) of 21 morphometric characters and values of two meristic characters in Oyama's series of Hynobius specimens in alcohol. For key to abbreviations of characters, see Meterials and Methods.

\begin{tabular}{cccccccccccc}
\hline Specimen & SVL & HL & IND & IOD & UEW & UEL & AGD & TRL & TAL & BTAW & MTAW \\
\hline KUM Hy61A & 59.2 & 14.2 & 3.5 & 3.6 & 1.9 & 3.3 & 31.2 & 45.0 & 36.0 & 5.8 & 2.9 \\
KUM Hy61B & 62.9 & 14.5 & 3.1 & 3.7 & 2.1 & 3.5 & 33.6 & 48.4 & 35.2 & 5.6 & 3.2 \\
KUM Hy61C & 61.0 & 14.2 & 3.3 & 3.6 & 2.0 & 3.5 & 32.6 & 46.8 & 37.0 & 6.1 & 4.8 \\
KUM Hy61D & 64.2 & 14.7 & 3.5 & 3.7 & 2.0 & 3.4 & 35.0 & 49.5 & 39.3 & 6.5 & 3.6 \\
KUM Hy61E & 47.3 & 12.6 & 2.8 & 3.1 & 1.8 & 3.0 & 24.8 & 34.7 & 29.2 & 4.7 & 3.1 \\
\hline \hline MTAH & MXTAH & FLL & HLL & 2FL & 3 FL & $3 T L$ & $5 T L$ & VTW & VTL & UJTN & VTN \\
\hline 3.5 & 4.9 & 14.8 & 17.7 & 2.3 & 2.3 & 3.9 & 0.8 & 3.2 & 3.4 & 66 & 51 \\
4.0 & 4.7 & 14.5 & 18.6 & 2.1 & 2.2 & 4.1 & 0.9 & 2.6 & 3.3 & 68 & 59 \\
6.4 & 6.4 & 12.8 & 16.8 & 2.1 & 2.0 & 3.9 & 0.9 & 3.2 & 3.2 & 62 & 50 \\
4.8 & 5.4 & 13.8 & 17.8 & 2.1 & 2.1 & 4.1 & 0.6 & 3.3 & 3.7 & 63 & 49 \\
4.5 & 4.5 & 11.1 & 14.9 & 1.7 & 1.7 & 3.5 & 0.7 & 2.5 & 2.6 & - & - \\
\hline
\end{tabular}

which he moved after the description, and at the Kumamoto City Museum where a part of Oyama's collection is currently stored $(\mathrm{H}$. Minei, personal communication). Although we failed to find specimens indicated as the name-bearing type, we could find five relevant specimens (hereafter called "Oyama's series") in the collection of Kyushu University.

We first examined Oyama's series (Table 1) with reference to Oyama's (1947) description of $H$. $n$. yatsui, and then compared the series with Species $B$ and $H$. naevius. We used 403 specimens of Species B from Chubu, Kinki, Shikoku, and Kyushu, and 255 specimens of $H$. naevius from Chugoku and Kyushu, including both sexes. These specimens are identical to those used by Tominaga and Matsui (2007) and represent 37 local samples including 19 samples of Species B and 18 samples of $H$. naevius (Table 2). We could identify sex and maturity status of each specimen in Oyama's series by observation of the gonads. However, due to the insufficient number of specimens in the series for statistical analyses, we combined sexes and used all adults (one male and three females) of the series together for morphological comparisons, although some morphological characters are known to vary sexually in Species B (Tominaga et al., 2005b).

Following Tominaga et al. (2005b), we measured 21 morphometric characters (SVL [snout vent length], HL [head length], IND [internarial distance], IOD [interorbital distance], UEW [upper eyelid width], UEL [upper eyelid length], AGD [axilla-groin distance], TRL [trunk length], TAL [tail length], BTAW [basal tail width], MTAW [medial tail width], MTAH [medial tail height], MXTAH [maximum tail height], FLL [forelimb length], HLL [hindlimb length], 2FL [second finger length], 3FL [third finger length], 3TL [third toe length], 5TL [fifth toe length], VTW [vomerine tooth series width], and VTL [vomerine tooth series length]), and counted two meristic characters (UJTN [number of upper jaw teeth] and VTN [number of vomerine teeth]).

We first performed a canonical discriminant analysis (CANDISC; SAS, 1990) for 37 local samples and Oyama's series using 20 morphometric characters (all but TAL, which contained missing values) to detect the local sample or samples most similar to Oyama's series. Also, using Mahalanobis distances thus obtained, we employed multi-dimensional scaling (MDS; Lessa, 1990) analysis to visualize overall similarities between Oyama's series and local samples. All measurements were log-transformed in these multivariate analyses. Furthermore, we compared seven morphological characters (SVL, TAL/SVL, MTAW/MTAH, VTW/VTL, 5TL/3TL, UJTN, and VTN; Tominaga et al., 2005b), known to exhibit definite geographic variation in Species B and $H$. naevius, between Oyama's series and local samples by multiple comparisons by using Dunnett's (Zar, 1984) or Steel's method (Steel, 1959; Zar, 1984). From these univariate analyses, we omitted one sample
Table 2. Local groups, locality names (numbers), and sample sizes for species included in the morphological analysis.

\begin{tabular}{|c|c|c|c|c|}
\hline \multirow{2}{*}{ Species } & \multirow{2}{*}{$\begin{array}{l}\text { Local } \\
\text { sample } \\
\text { group }\end{array}$} & \multirow{2}{*}{$\begin{array}{l}\text { Locality name } \\
\text { (sample number) }\end{array}$} & \multicolumn{2}{|c|}{ Sample size } \\
\hline & & & Male & Female \\
\hline H. sp. B & Chubu & Maze (1) & 12 & 8 \\
\hline H. sp. B & Chubu & Fujihashi (2) & 20 & 15 \\
\hline H. sp. B & Kinki & Tsuchiyama (3) & 8 & 4 \\
\hline H. sp. B & Kinki & Misugi (4) & 6 & 6 \\
\hline H. sp. B & Kinki & Izumi (5) & 7 & 9 \\
\hline H. sp. B & Kinki & Kudoyama (6) & 11 & - \\
\hline H.sp. B & Kinki & Kozagawa (7) & 7 & 5 \\
\hline H. sp. B & Shikoku & Higashiiyayama (8) & 40 & 16 \\
\hline H. sp. B & Shikoku & Tosayama (9) & 15 & 4 \\
\hline H. sp. B & Shikoku & Saijo (10) & 11 & 10 \\
\hline H. sp. B & Shikoku & Oda (11) & 3 & 6 \\
\hline H. sp. B & Kyucshu-B & Kitakyushu-B (30) & 20 & 14 \\
\hline H. sp. B & Kyucshu-B & Amagi-B (31) & 19 & 17 \\
\hline H. sp. B & Kyucshu-B & Ume (32) & 11 & 10 \\
\hline H. sp. B & Kyucshu-B & Yabe (33) & 21 & 3 \\
\hline H. sp. B & Kyucshu-B & Itsuki (34) & 12 & 4 \\
\hline H. sp. B & Kyucshu-B & Miyanojo (35) & 10 & 8 \\
\hline H. sp. B & Kyucshu-B & Tano (36) & 13 & 7 \\
\hline H. sp. B & Kyucshu-B & Kanoya (37) & 6 & 4 \\
\hline H. naevius (sp. A) & Chugoku & Katsuta (12) & 6 & - \\
\hline H. naevius (sp. A) & Chugoku & Nichinan (13) & 14 & - \\
\hline H. naevius (sp. A) & Chugoku & Yuki (14) & 9 & - \\
\hline H. naevius (sp. A) & Chugoku & Daito (15) & 8 & - \\
\hline H. naevius (sp. A) & Chugoku & Fukutomi (16) & 4 & - \\
\hline H. naevius (sp. A) & Chugoku & Geihoku (17) & 10 & - \\
\hline H. naevius (sp. A) & Chugoku & Yoshiwa (18) & 22 & - \\
\hline H. naevius (sp. A) & Chugoku & Asahi (19) & 6 & 3 \\
\hline H. naevius (sp. A) & Chugoku & Toyota (20) & 16 & 7 \\
\hline H. naevius (sp. A) & Kyucshu-A & Kitakyushu-A (21) & 24 & 6 \\
\hline H. naevius (sp. A) & Kyucshu-A & Wakamiya (22) & 7 & - \\
\hline H. naevius (sp. A) & Kyucshu-A & Amagi-A (23) & 13 & 8 \\
\hline H. naevius (sp. A) & Kyucshu-A & Fukuoka (24) & 16 & 8 \\
\hline H. naevius (sp. A) & Kyucshu-A & Sechiwara (25) & 6 & 4 \\
\hline H. naevius (sp. A) & Kyucshu-A & Tara-dake (26) & 5 & 7 \\
\hline H. naevius (sp. A) & Kyucshu-A & Aki (27) & 10 & - \\
\hline H. naevius (sp. A) & Kyucshu-A & Kokonoe (28) & 18 & 4 \\
\hline H. naevius (sp. A) & Kyucshu-A & Kikka (29) & 10 & 4 \\
\hline
\end{tabular}


of $H$. naevius from Chugoku (sample 16), which was insufficient in size. Finally, we compared the gross pattern of body markings between Oyama's series and each local sample following Tominaga et al. (2005b). Validity of the name $H$. n. yatsui was examined with reference to ICZN (2000).

\section{RESULTS}

\section{Status of Oyama's series with reference to the descrip- tion of Hynobius naevius yatsui}

Many urodelan specimens collected by Junji Oyama $(\mathrm{H}$. Minei, personal communication) were stored in the Faculty of Agriculture, Kyushu University, and these included five specimens collected from Aso district and identified as $H$. naevius (sensu lato). These specimens consisted of one adult male, three adult females, and one juvenile of unknown sex. Only the date (from 4 March 1939 to 27 September 1940) and locality (Aso district, which corresponds to the type locality of $H$. n. yatsui) of collection were indicated on the label attached to the specimens, and neither scientific name nor Japanese name was given. No specimens collected by Oyama and referable to $H$. naevius were in the collections of Kumamoto University or Kumamoto City Museum.

Measurements and counts of Oyama's series are shown in Table 1. Unfortunately, body color of the series has faded seriously and did not permit us to know the original ground color. However, features of the markings, i.e., relatively small, light markings on the dorsal surface of the head and trunk, could be well recognized, as shown in Fig. 1. Specimens were small in body size and slender in habitus. They had a thick, short tail with rounded tip as shown by small TAL/SVL and large MTAW/MTAH values (see below). Except for ground color, all these features of Oyama's series agreed with the original description of $H$. n. yatsui (Oyama, 1947: ground color pale reddish purple with white markings like those of the normal type of $H$. naevius; extremely elegant and can be differentiated from the normal type at a glance; not so stout as the normal type; tail relatively short with its tip not flattened).

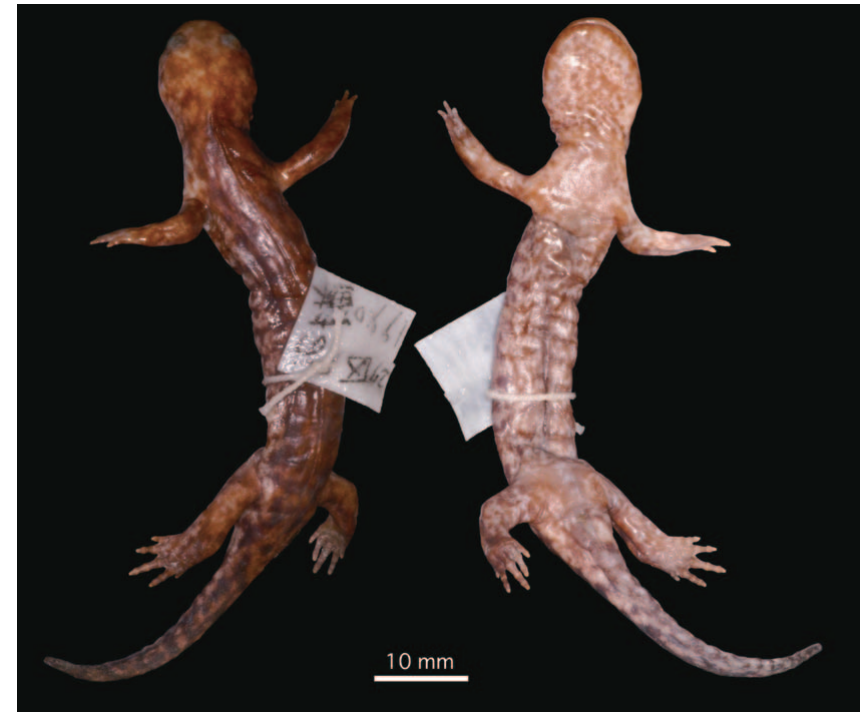

Fig. 1. Dorsal (left) and ventral (right) views of an adult male salamander of Oyama's series (KUM Hy61A, lectotype of $H$. n. yatsui).

\section{Relationships of Oyama's series to Species B and Hynobius naevius}

The eigenvalues of the first (CAN1) and second (CAN2) axes resulting from CANDISC accounted for 14.15 (proportion=0.69) and 1.98 (proportion=0.10), respectively, and two groups, one including $H$. naevius and the other including Oyama's series and Species B, were nearly completely separated by these axes (Fig. 2). Within the latter group, ranges of the three regional samples of Species B (Chubu-Kinki, Shikoku, and Kyushu) overlapped with each other. All four of Oyama's specimens were positioned within the range of Kyushu samples of Species B, although three of them also overlapped with Chubu-Kinki samples. The MDS reached convergences after 13 iterations with a Kruskal stress value of 0.044 and an uncorrected distance correlation of 1.00 ,

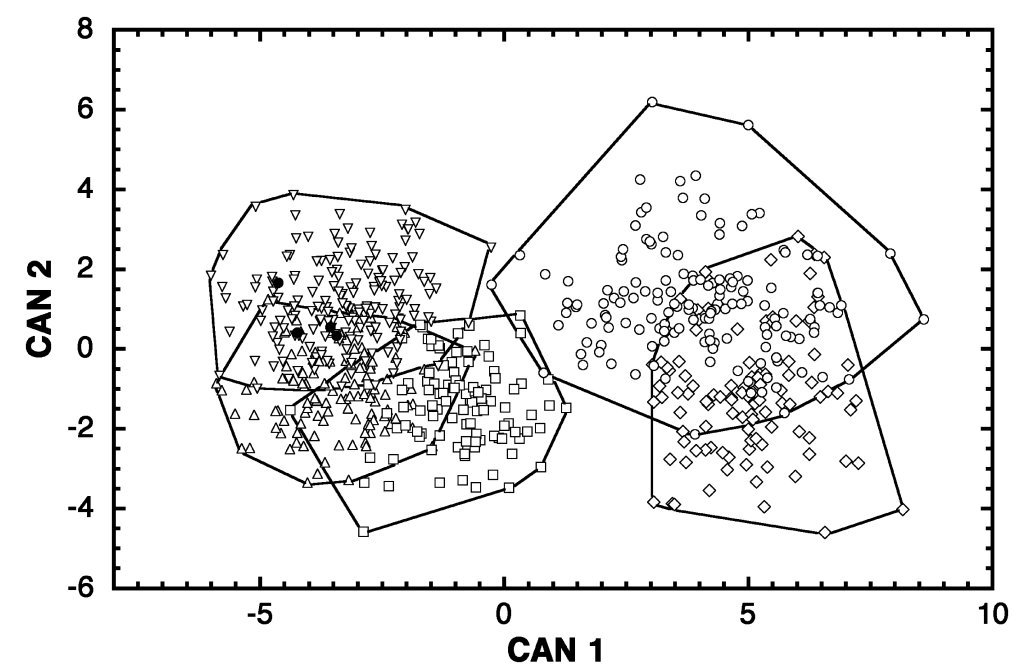

Fig. 2. Plots of first against second canonical axis based on CANDISC for specimens of Oyama's series and 37 local samples. Closed circles, specimens of Oyama's series; open inverted triangles, $H$. sp. B from Kyushu (Kyushu-B); open squares, $H$. sp. B from Shikoku; open triangles, $H$. sp. B from Chubu-Kinki; open circles, $H$. naevius from Kyushu (Kyushu-A); open diamonds, $H$. naevius from Chugoku. 


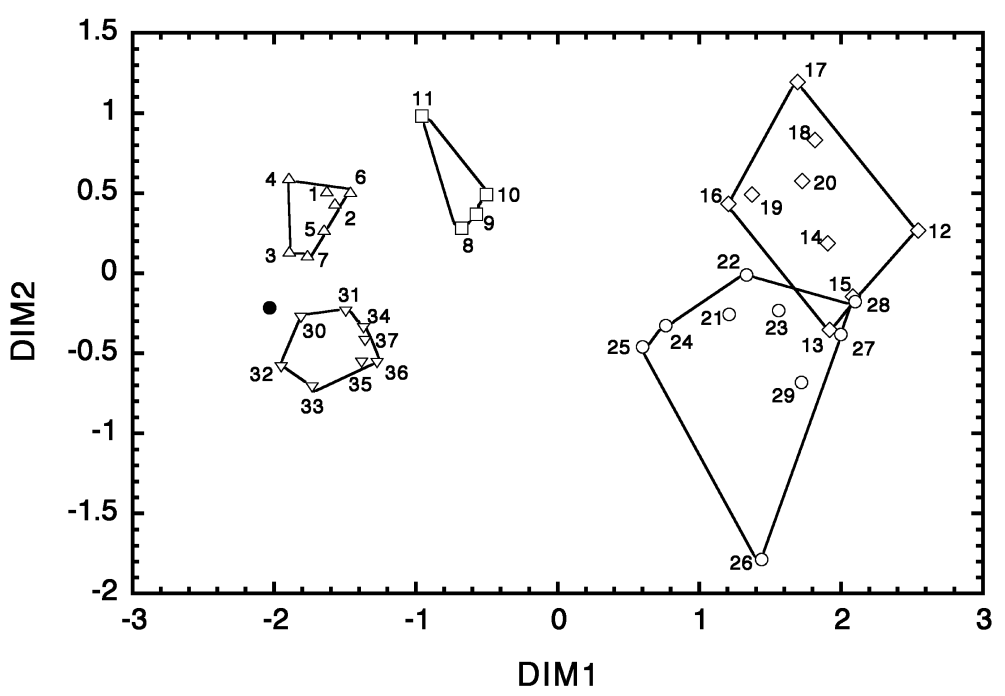

Fig. 3. Relationships between sample of Oyama's series and 37 local samples resolved from MDS using Mahalanobis distance. Closed circle, Oyama's series; open inverted triangles, $H$. sp. B from Kyushu (Kyushu-B); open squares, $H$. sp. B from Shikoku; open triangle, $H$. sp. B from Chubu-Kinki; open circles, $H$. naevius from Kyushu (Kyushu-A); open diamond, $H$. naevius from Chugoku. For sample numbers, refer to Table 2.

and Oyama's series was morphometrically most similar to Kyushu samples of Species B (Fig. 3).

Similar results were obtained in the comparisons using seven univariate characters. Specimens of Oyama's series had relatively small body size, with a mean SVL of $61.8 \mathrm{~mm}$ (range=59.2-64.2 mm). Oyama's series did not differ significantly from all samples of Species $B$, but was significantly smaller in SVL than more than half of $H$. naevius (samples 12-15, 21-24, 26-29; $P<0.05)$.

Tails of Oyama's series were very short and thick, with a median TAL/SVL of $60.7 \%$ (range $=56.0-61.2 \%$ ), and did not differ significantly from samples 3 from Kinki and 30-33 from Kyushu of Species B. All the remaining samples, including $H$. naevius (samples 12-20 from Chugoku and samples 21-29 from Kyushu) and Species B (samples 1, 2, 4-7 from Chubu-Kinki, samples 8-11 from Shikoku, and samples 34-37 from Kyushu) had significantly larger TAL/ SVL values than Oyama's series $(P<0.05)$. The median of MTAW/MTAH in Oyama's series was $77.5 \%$ (range $=75.0$ $82.9 \%$ ) and did not differ from the Species B samples except for samples 10-11 from Shikoku, which had a significantly thicker tail than Oyama's series. Oyama's series did not differ from seven samples $(12,13,17-19,22,27)$ of $H$. naevius, but had significantly thicker tail than the remaining 10 samples $(14,15,20,21,23-26,28,29)$ of the species.

Specimens of Oyama's series had a poorly developed fifth toe, with a median 5TL/3TL of $21.2 \%$ (range=14.7$23.1 \%)$. Fifteen samples $(1-6,8,10,11,30,32-36)$ of Species $B$ and three samples $(13,17,22)$ of $H$. naevius did not differ from Oyama's series in this ratio. In contrast, samples 7 and 9 of Species B and 14 samples (12, 14, 15, 18-21, 23-29) of $H$. naevius had significantly larger 5TL/3TL than Oyama's series, whereas two samples $(31,37)$ of Species $B$ from Kyushu showed significantly smaller values than Oyama's series $(P<0.05)$.

The vomerine tooth series in Oyama's series was very deep, with a median VTW/VTL of $91.4 \%$ (range=81.0-
99.6\%). Oyama's series did not significantly differ in this ratio from all samples of Species $B$ from Chubu-Kinki and Kyushu. In contrast, all four Shikoku samples of Species B and all samples of $H$. naevius had significantly shorter vomerine tooth series than Oyama's series $(P<0.05)$. Similarly, Oyama's series (median $=50.5$, range $=49-59$ ) did not differ in VTN from all samples of Species B from ChubuKinki and Kyushu, but showed significantly larger values in this character than all Shikoku samples of Species B and all samples from Chugoku and one sample (27) from Kyushu of $H$. naevius $(P<0.05)$.

Oyama's series had a moderate number of upper jaw teeth (UJTN, median=64.5; range $=62-68$ ), which did not significantly differ from those of three samples $(3,6,7)$ from Chubu-Kinki, one (11) from Shikoku, and all (30-37) Kyushu samples of Species B. The UJTN of Oyama's series was significantly larger than that of four samples $(1,2,4,5)$ from Chubu-Kinki and three (8-10) from Shikoku of Species B, and one sample (15) from Chugoku of $H$. naevius, whereas the value was significantly smaller than that of three samples $(14,17,20)$ from Chugoku and eight $(21,23-29)$ from Kyushu of $H$. naevius $(P<0.05)$. Oyama's series thus did not significantly differ from sample 3 from Kinki and samples 30 , 32 , and 33 from Kyushu of Species B in any of the seven characters compared.

\section{DISCUSSION}

\section{Validity of Hynobius naevius yatsui in light of the ICZN}

Results in this study indicate that Oyama's series corresponds to $H$. n. yatsui described by Oyama (1947). Oyama (1947) did not designate a type series for H. n. yatsui, and we could not find specimens labeled as the type. However, J. Oyama surely left specimens of salamanders (Oyama's series) at Kyushu University $(\mathrm{H}$. Minei, personal communication), to which he belonged when he dealt with $H$. n. yatsui (Oyama, 1940, 1947). The specimens in Oyama's series are clearly indicated to have been collected from the Aso district 
(the type locality of $H$. n. yatsui) from 4 March 1939 to 27 September 1940, a period that included his first report on this subspecies at the 48th meeting of the Japanese Association of Anatomists (1 August 1940: Oyama, 1940) and before his second report (Oyama, 1947). These facts strongly suggest that Oyama's series represents specimens that were used for the description of $H$. n. yatsui. Our study also indicates that Oyama's series is morphologically highly similar to some specimens, especially those from Kyushu, of Species B (or Group B of $H$. naevius: Tominaga et al., 2005a, b, 2006), rather than to $H$. naevius (Group $A$ of $H$. naevius in Tominaga et al., 2005a, b, 2006). Therefore, at issue is the validity of the name $H$. n. yatsui in light of the Code (ICZN, 2000).

This taxonomic issue arose from Oyama's proposal of the name " $H$. n. yatsui" in 1940. In the abstract published after the meeting, Oyama (1940) only listed the name with other Hynobius species occurring in Kyushu. Then, after interruption of his study by the Pacific War, Oyama (1947) reported $H$. n. yatsui again in a short note. This time, however, his report included the locality of specimens used, morphological features of $H$. $n$. yatsui, and its morphological distinction from $H$. n. naevius, as shown below. He also referred to the morphological similarity of $H$. $n$. yatsui to the southern Kyushu type of salamander recognized by Sato (1943), who listed " $H$. n. yatsui" as a synonym of $H$. naevius. After Oyama (1947), however, the name $H$. n. yatsui never appeared in publications until recently, when our previous work (Tominaga et al., 2003) referred to it. Frost (2004) included the name in the synonym list for $H$. naevius.

The name $H$. $n$. yatsui Oyama ,1940, first proposed in an abstract of a meeting presentation (Oyama ,1940) cannot be recognized as available (Criteria of Availability: Chapter 4 of the Code), because, as noted above, this abstract does not include a description or definition of characters that differentiate $H$. n. yatsui from other taxa (Article 13.1.1 of the Code), nor refers to bibliographic references to published statements (Article 13.1.2).

In contrast, Oyama (1947) included two important sentences: "It $(=H$. $n$. yatsui; our notation) is less stout than the normal type of $H$. naevius and has a relatively short tail whose tip is not flat...There is a mention of specimens from Mt. Takakuma, Southern Kyushu, in the section of $H$. naevius in the "Monograph of the Tailed Batrachians of Japan" by the late Dr. Sato, and this Southern Kyushu population is thought to be similar to a subspecies which I describe here." The description of $H$. n. yatsui in Oyama (1947) thus includes not only a description and the definition of its character states in words that are purported to differentiate the taxon (Article 13.1.1), but also a bibliographic reference to published statements (Article 13.1.2). Thus the name " $H$. $n$. yatsui" in Oyama (1947) is recognized as available. The date of publication (sensu Article 21) for $H$. n. yatsui must be 25 November 1947, when Issue 7 of Volume 57 of Zoological Magazine was published in print (Article 21.2), including Oyama (1947).

In addition, the published matter of Oyama (1947) satisfies all criteria of publication, because it was issued for the purpose of providing a public and permanent scientific record (Article 8.1.1), was obtainable by purchase (Article 8.1.2), was produced in an edition containing simultaneously obtainable copies by a method that assures numerous identical and durable copies (Article 8.1.3), and was produced on paper by letterpress (Article 8.4). Further, the name $H$. $n$. yatsui Oyama, 1947 fulfills the requirement relating to mandatory use of the Latin alphabet (Article 11.2). Oyama (1947) stated that he dedicated the name to his supervisor Prof. Naohide Yatsu (Article 11.3) and applied binominal nomenclature (11.4). Moreover, this name was used as valid when proposed (11.5). Thus, the name "H. n. yatsui" satisfies every requirement of Article 11.

With respect to the type series, Oyama (1947) designated neither a holotype nor syntypes (Article 73 of the Code) for $H$. n. yatsui. Therefore, there is no possibility that the name-bearing type was lost or destroyed, while morphological features of the specimens stored in Kyushu University (Oyama's series) are consistent with those of $H . n$. yatsui in the original description. Although no specimens were defined as types, we consider that these specimens (Oyama's series) correspond to the specimens used for the description of $H$. n. yatsui, as discussed above. The specimens of Oyama's series should thus be regarded as comprising the type series used by Oyama (1947) for description of $H$. n. yatsui (Article 72.4.1.1.). Furthermore, because this name was established before 2000 , each of the specimens should be regarded as a syntype of this subspecies (Articles 72.1.1 and 73.2).

Species $B$, while distinct from $H$. naevius at the species level, is considered to be identical to the syntypes of $H$. $n$. yatsui. If this species is not officially given a scientific name, taxonomic confusion will result. To prevent this, we designate one male syntype of $H$. n. yatsui as the lectotype of this subspecies, following Article 74.7.3. In his paper and on labels of his specimens, Junji Oyama applied the locality name "Aso" to a wide area that encompasses present Aso City and surrounding regions (e.g., "Aso-Mamihara" corresponding to present Yamato-cho). Therefore, we cannot show the precise type locality (e.g., latitude and longitude) of $H$. n. yatsui, even though announcement of a detailed type locality is recommended (Recommendation $74 \mathrm{C}$ of the Code).

\section{Description of Hynobius yatsui Oyama, 1947}

Hynobius yatsui Oyama, 1947

<Japanese name: Kogata-Buchi-Sanshou-uwo>

(Fig.1)

Pesudosalamandra stjnegeri (sic): Tago, 1931, p. 189, fig. 22. Hynobius naevius yatsui (nomen nudum): Oyama, 1940, p. 35.

H. naevius (part, Southern Kyushu local type): Sato, 1943, p. 206.

H. naevius yatsui: Oyama, 1947, p. 106.

H. naevius (part, Southern Kyushu Type): Sato et al., 1994, p. 119 , fig. $2 \mathrm{C}$.

H. naevius (part, Type B): Tominaga et al., 2003, p. 1467. $H$. naevius (part, Group B): Tominaga et al., 2005a, p. 921; Tominaga et al., 2005b, p. 1229, fig. 7A, B, and E. H. naevius (part, Group II): Sakamoto et al., 2005, p. 67. $H$. naevius (part, Clade 3+4): Tominaga et al., 2006, p. 677.

\section{Lectotype}

KUM (Kyushu University Museum) Hy61A, adult male 
from the Aso district (details unknown), Kumamoto Prefecture, Kyushu, collected 27 September 1940, probably by Junji Oyama.

\section{Paralectotypes}

A total of four specimens, all from the Aso district, Kumamoto Prefecture (details unknown), collected in 1939 and 1940, probably by Junji Oyama. KUM Hy61B, female collected on 4 March 1939; KUM Hy61C, female, 1 March 1940; KUM Hy61D, female, 11 June 1940; KUM Hy61E, immature individual of unknown sex, 27 May 1940.

\section{Referred specimens}

KUHE (Kyoto University, Graduate School of Human and Environmental Studies) 32250-32258, 32260, 3345633459, 33461-33465, 33482 from Gero-shi (formerly Mazemura), Gifu Prefecture; KUHE27396-27399, 27406-27408, 27531-27533, 27571, 27632, 27636-27640, 27838, 2876228766, 28770-28771, 28774-28776, 28781, 33361-33362, TPC (Mr. Tanabe's private collection) 2910, 3044-3046 from Ibigawa-cho (formerly Fujihashi-mura), Gifu Prefecture; KUHE6051, 6378, 7074, 7504, 11530, 28477, 28710, TPC 2194, 2799, 2804, 2805, 3193 from Koka-shi (formerly Tsuchiyama-cho), Shiga Prefecture ; KUHE27007-27011, 27732, 32508-32511, 32527, TPC2687 from Tsu-shi (formerly Misugi-mura), Mie Prefecture ; KUHE5416, 5973, 33451, 33452, 34563, 34564, TPC1977, 2695, 2852-2854, 2986-2990 from Izumi-shi, Osaka Prefecture; KUHE 22790-22791, 22893, 28961-28962, 29253, TPC 31073108, 3112-3114 from Kudoyama-cho, Wakayama Prefecture; KUHE9595, 22793-22794, 26096-26097, 26897, 28671-28672, 29669-29672 from Kozagawa-cho, Wakayama Prefecture; KUHE8335-8337, 8341-8355, 8357-8360, 8362-8364, 28044-28045, TPC1238-1240, $1243-1244,1247,1597,1599-1600,1959-1961,1963-$ 1964, 2001-2002, 2093-2096, 2198, 2607, 3018-3021, 3064, 3138-3139 from Miyoshi-shi (formerly Higashiiyayama-son), Tokushima Prefecture; KUHE5971-5972, 10205-10210, 18035-18041, TPC2118, 2707-2709 from Kochi-shi (formerly Tosayama-mura), Kochi Prefecture; TPC 1436, 1946-1954, 2016, 2170-2172, 2600-2601, 2995, 2997-2999, 3033 from Saijo-shi, Ehime Prefecture; KUHE21711-21712, 21785-21786, TPC2596, 2598-2599, 2689-2690 from Uchiko-cho (formerly Oda-cho), Ehime Prefecture; KUHE13605, 26706, 27127, 27129, 27161-27162, 27268-27269, 27911, 28201, 28378, 28384-28385, 2849728508, 28571-28573, 29958, 32585-32586, STPC (Mr. Sato's private collection) three unnumbered specimens from Kitakyushu-shi, Fukuoka Prefecture; KUHE26092, 26168, 26171, 26173, 26635-26637, 26859, 27143, 27808, 2788627889, 27893-27896, 27901-27902, 27906-27907, 28375, 28485-28486, 28489-28493, 28675, 29254-29255, 2936529366, 34566 from Asakura-shi (formerly Amagi-shi), Fukuoka Prefecture; KUHE14032, 22888, 22890-22891, 2496824969, 25098, 26093, 27381-27383, 28846, 29988, 34565, OMNH (Osaka Museum of Natural History) Am3120-3121, STPC two unnumbered specimens from Saiki-shi (formerly Ume-machi), Oita Prefecture; KUHE7502-7503, 26072, 27302, 28007-28010-28015, OMNHAm10141-10148, 10150 -10151, 10155 from Yamato-cho (formerly Yabe-machi), Kumamoto Prefecture; KUHE34568, 34620-34623, 34626-
34629, 34631-34633, 34635, 34637-34639 from Itsuki-mura, Kumamoto Prefecture; KUHE27329, 28120-28122-28125, 29948, 29949, 32098-32105, 34640, one male unnumbered from Satsuma-cho (formerly Miyanojo-cho), Kagoshima Prefecture; KUHE 6436-6440, 18523, 19035, 28109-28112, 29955-29957, 30213-30215, 32079-32081 from Miyazakishi (formerly Tano-cho), Miyazaki Prefecture; KUHE2809828099, 32088-32095 from Kanoya-shi, Kagoshima Prefecture.

\section{Diagnosis}

A member of the naevius group (Sato, 1943) of Hynobius, with a cylindrical tail and very few large, pigmentless ova per clutch, in contrast to a compressed tail and a large number of small, pigmented, ova per clutch in the nebulosus group; breeding in water flowing underground, unlike the remaining members of the naevius group that breed in open waters; most similar to $H$. naevius in appearance, but with a smaller body, relatively narrower head, shorter trunk, more cylindrical and shorter tail, relatively longer vomerine tooth series, mottled dorsum, and large molecular differences.

\section{Redescription of lectotype of Hynobius naevius yatsui Oyama, 1947}

Measurements and counts are summarized in Table 1 together with those of the paralectotypes. Body slender. Head moderately depressed, distinctly longer $(\mathrm{HL}=24.0 \%$ SVL) than broad ( $\mathrm{HW}=17.4 \% \mathrm{SVL})$. Number of costal grooves including axillary groove 13. Limbs short (FLL=25.0\% SVL, HLL $=29.9 \%$ SVL), stout. Fore- and hindlimbs separated by two costal folds when adpressed. Tail shorter ( $T A L=60.8 \% \mathrm{SVL}$ ) than trunk (TRL $=76.0 \% \mathrm{SVL})$, vertically oval at base (BTAW=9.8\% SVL) and middle (MTAW $=4.9 \%$ SVL, MTAH $=5.9 \%$ SVL), not keeled, gradually flattening to round tip. Fifth toe very short $(5 T L=1.4 \% S V L)$. Vomerine teeth in two small, obliquely arched series, nearly touching at midline, forming a very deep " $\mathrm{V}$ ". Combined series longer than wide (VTW/VTL=0.94). No small protuberance at the anterior tip of vent.

\section{Color in alcohol of lectotype}

Color in preservative is faded. Light brown dorsally with discontinuous brownish-white markings, which tend to fuse on tail. Ventrally, ground color is lighter brown with continuous white markings (Fig. 1).

\section{Variation}

To facilitate to describe more general features of $H$. yatsui, morphological variations in referred specimens from various localities (Tominaga et al., 2005b) are incorporated to the type series. Hynobius yatsui (Group B in Tominaga et al., 2005b) is characterized by relatively small body size (mean SVL $\pm 1 S D=59.8 \pm 4.9 \mathrm{~mm}$ in males and $61.7 \pm 5.3 \mathrm{~mm}$ in females), which is correlated negatively with latitude, longitude, and mean annual temperature, and positively with altitude and annual precipitation. There is slight sexual dimorphism in body proportions; males have relatively larger features related to the head and relatively longer limbs and tails, while females have larger SVL, a relatively longer trunk, and more numerous upper and lower jaw teeth, in a sample from Asakura-shi, Kyushu (Sample 31 in Table 2). 
Chubu-Kinki and Kyushu samples have a relatively longer vomerine tooth series and relatively shorter tail than the Shikoku samples. A part of Shikoku and Kyushu samples have well-developed fifth toes. Shikoku samples have a smaller number of jaw teeth than the others, whereas Kyushu samples have a larger, and Shikoku samples have a smaller, number of vomerine teeth than the Chubu-Kinki samples.

There is no sexual dimorphism in color pattern in a sample from Asakura-shi, Kyushu. Except for one sample from eastern Shikoku (Sample 8 in Table 2), the species has the dorsum reddish-purple in ground color, with discontinuous, brownish-white markings or white dots. In many specimens from Chubu and northern Kinki, the white dots on the dorsum are very small. The exceptional eastern Shikoku sample has a black dorsum with continuous bright yellow markings. The species usually has the flank reddish-purple in ground color, with white markings that tend to be smaller in some specimens from Chubu-Kinki and Kyushu than in others. Generally, the tail is darker in ground color, with markings larger in size than on the trunk. Ventral ground color is light gray to light reddish-purple, with relatively small, white markings.

\section{Comparisons}

The tail of $H$. yatsui is cylindrical, and this shape differentiates it from the following species that have the tail compressed at least in the posterior half: from Japan, $H$. abei Sato, 1934; $H$. dunni Tago, 1931; $H$. hidamontanus Matsui, 1987; H. nebulosus (Temminck and Schlegel, 1838); $H$. nigrescens Stejneger, 1907; $H$. retardatus Dunn, 1923; $H$. takedai Matsui and Miyazaki, 1984; H. tokyoensis Tago, 1931; and $H$. tsuensis Abé, 1922; from Korea, H. leechii Boulenger, 1887; $H$. quelpaertensis Mori, 1928; and $H$. yangi Kim, Min, and Matsui, 2003; from China, $H$. amjiensis Gu, 1992; H. chinensis Günther, 1889, H. guabangshanensis Shen, Deng, and Wang, 2004, H. maoershanensis Zhou, Jiang, and Jiang, 2006; $H$. yiwuensis Cai, 1985; and $H$. yunanicus Chen, Qu, and Niu, 2001; and from Russian Turkestan, H. turkestanicus Nikolskii, 1910.

Hynobius yatsui, with dorsal marking, is distinguished from $H$. boulengeri (Thompson, 1912) and $H$. katoi Matsui, Kokuryo, Misawa, and Nishikawa, 2004 from Japan, which have a nearly monotonous, dark-brown dorsum. Three species from Taiwan $(H$. arisanensis Maki, 1922; $H$. formosanus Maki, 1922; and $H$. sonani (Maki, 1922)) have a markedly longer vomerine tooth series than $H$. yatsui. The remaining four species from Japan $(H$. kimurae Dunn, 1923; $H$. naevius; $H$. okiensis Sato, 1940; and H. stejnegeri Dunn, 1923) are more similar to $H$. yatsui in appearance. However, $H$. okiensis has a posteriorly compressed tail and long, fragile limbs, and is equipped with a small protuberance at the anterior tip of the vent in adult males (vs. cylindrical tail; short, stout limbs; and lacking a protuberance on the vent in $H$. yatsui). Hynobius stejnegeri has a decidedly larger body and large, orange-yellow blotches on a black dorsum (vs. small body and brownish-white markings or white dots on a reddishpurple dorsum in $H$. yatsui). Some specimens of $H$. yatsui from Shikoku are similar to $H$. stejnegeri in coloration, but have a much smaller body and shorter limbs. Hynobius kimurae usually has clear yellow spots on the dorsum, but lacks marking on the flanks and ventral side (vs. mottled with brownish-white dorsally and marked with white laterally and ventrally in $H$. yatsui).

The last species, $H$. naevius, with which $H$. yatsui had been synonymized, is naturally most similar in morphology. However, $H$. naevius is larger in body size (mean $S V L=73.0$ $\mathrm{mm}$ vs. $60.5 \mathrm{~mm}$ in $H$. yatsui), with a longer, less cylindrical tail (medians of MTAW/MTAH and TAL/SVL $=70 \%$ and $74 \%$ vs. $80 \%$ and $66 \%$, respectively, in $H$. yatsui) and less deeply curved vomerine teeth series (median of VTW/VTL $=133 \%$ vs. $97 \%$ in $H$. yatsui). In coloration, $H$. naevius usually lacks a mottling pattern on the bluish-purple dorsum (vs. brownishwhite mottling on a reddish purple dorsum in $\mathrm{H}$. yatsui), and mostly has pale white marking on the lateral side of the trunk and tail (vs. white marks in $H$. yatsui).

\section{Etymology}

Junji Oyama dedicated the specific name "yatsui" to Prof. Naohide Yatsu of Tokyo Imperial University. Prof. Yatsu greatly contributed to the study of zoology in Japan, and was Oyama's supervisor.

\section{Range}

Known from the western part of Japan: Chubu District (Gifu and Aichi Prefectures), Kinki District except for Kyoto and Hyogo Prefectures, Shikoku District, and Kyushu District except for Saga and Nagasaki Prefectures.

\section{Fecundity and natural history}

The natural history of $H$. yatsui is poorly understood, and few egg sacs and larvae have been found in nature in Kyushu despite our extensive field surveys. In Shikoku and Chubu, it lays eggs in very small, underground streams, where the larvae hatch and metamorphose without feeding. The clutch sizes of seven females from Gifu, Wakayama, and Kagoshima varied from 7 to19 (median=14), and the mean diameters of seven to 10 ova from these females ranged from 4.6 to $5.0 \mathrm{~mm}$ (mean $\pm S D=4.66 \pm 0.28 \mathrm{~mm}$ ). The breeding season is early May in Chubu (Yamagami et al., 2007), and from late May to June in Shikoku (Tanabe, 2002; Matsui, unpublished data), but is unknown in other regions.

Hynobius yatsui occurs syntopically with $H$. naevius in northeastern to central Kyushu (Tominaga et al., 2003; Sakamoto et al., 2005). Similarly, it is found syntopically with $H$. kimurae in Chubu and northern Kinki; with $\mathrm{H}$. boulengeri in southern Kinki, Shikoku, and part of central Kyushu; and with $H$. stejnegeri from central to southwestern Kyushu. Only in southeastern Kyushu are coexisting Hynobius species absent. In all these coexisting species, body sizes are larger than in $H$. yatsui, and oviposition and larval growth occur in relatively wide, open montane streams (Tominaga et al., 2005b).

\section{ACKNOWLEDGMENTS}

We are grateful to T. Mori, H. lida, and $\mathrm{H}$. Minei of Kyushu University for allowing us to examine type series under their care. We thank K. Nishikawa, M. Sakamoto, S. Sato, and S. Tanabe for valuable advice throughout our study and $\mathrm{T}$. Hikida and $\mathrm{H}$. Ota for valuable comments on the manuscript. We are also much indebted to H. Ashida, T. Hayashi, S. Ikeda, S. Ichihara, M. Kato, K. Kawano, S. Matsuzuki, K. Matsuo, Y. Misawa, K. Nishikawa, S. Okada, S. 
Sato, T. Shimada, Z. Shimizu, T. Sota, T. Sugahara, T. Sugihara, S. Tanabe, Y. Tatewaki, T. Utsunomiya, Y. Utsunomiya, M. Yamagami, E. Yamamoto, N. Yamanaka, and Y. Yasukawa for help in collecting specimens, and K. Hatooka, S. Okada, M. Sakamoto, S. Sato, and S. Tanabe for allowing us to examine specimens in their care. We also thank T. Hikida for assisting with statistical analyses. This work was supported by a Grant-in-Aid to M. Matsui (No. 11640697) from the Ministry of Education, Science and Culture, Japan, and a grant from the Ministry of Environment of Japan (formerly, the Environmental Agency of Japan).

\section{REFERENCES}

ICZN (2000) International Code of Zoological Nomenclature, 4th Ed Japanese text. The Union of Japanese Societies for Systematic Zoology, Sapporo

Lessa E (1990) Multidimensional analysis of geographic genetic structure. Syst Zool 39: 242-252

Oyama J (1940) Exhibition of wax models of Hynobius from Kyushu, showing body color in life. Acta Anat Nippon 16: 34-35

Oyama J (1947) Hynobius naevius yatsui. Zool Mag Tokyo 57: 106107

SAS (1990) SAS/STAT User's Guide. SAS Institute, Cary

Sakamoto M, Nishikawa K, Matsui M (2005) Two types of Hynobius naevius from the central region of Kyushu Island, Japan (Caudata: Hynobiidae). Curr Herpetol 24: 67-77

Sato I (1943) A Monograph of the Tailed Batrachians of Japan. Nippon Shuppansha, Osaka

Sato S, Kuramoto M, Ono Y (1994) Morphological variation in Hynobius naevius (Caudata: Hynobiidae) in Kyushu, Japan. Jpn J Herpetol 15: 119-125

Steel RGD (1959) A multiple comparison rank sum test: treatment versus control. Biometrics 15: 560-572

Tago K (1931) Newts and Salamanders. Geisoudo, Kyoto
Tanabe S (2002) Hynobius naevius (Amphibia). In: "Red Data Book of Kochi Prefecture (Animals)" Ed by Editorial Committee of Red Data Book of Kochi Prefecture, Kochi Prefecture, Kochi, pp 164-165

Temminck CJ, Schlegel H (1838) Repatlia. Les Sauriens. Les Batraciens. In "Fauna Japonica Auctore" Ed by PF de Siebold, Lugdunni Batavorum, Amsterdam, pp 122-123, PI VI

Tominaga A, Matsui M (2007) Estimation of the type locality of Hynobius naevius (Temminck and Schelegel. 1838), a salamander from Japan (Amphibia: Caudata). Zool Sci 24: 940-944

Tominaga A, Matsui M, Nishikawa K, Sato S (2003) Occurrence of two types of Hynobius naevius in northern Kyushu, Japan (Amphibia: Urodela). Zool Sci 20: 1467-1476

Tominaga A, Matsui M, Nishikawa K, Tanabe S, Sato S (2005a) Genetic differentiations of Hynobius naevius (Amphibia: Hynobiidae) as revealed by allozyme analysis. Biochem Syst Ecol 33: 921-937

Tominaga A, Matsui M, Nishikawa K, Tanabe S, Sato S (2005b) Morphological distinction of two genetic groups of Japanese salamander, Hynobius naevius (Amphibia, Caudata). Zool Sci 22: $1229-1244$

Tominaga A, Matsui M, Nishikawa K, Tanabe S (2006) Phylogenetic relationships of Hynobius naevius (Amphibia: Caudata) as revealed by mitochondrial $12 S$ and $16 \mathrm{~S}$ rRNA genes. Mol Phylogenet Evol 38: 677-684

Yamagami M, Nakazono H, Onodera S (2007) Notes on distribution and breeding ecology in a salamander, Hynobius naevius from northwestern part of Aichi Prefecture, Japan. Bull Herpetol Soc Jpn 2007: 137-143

Zar JH (1984) Biostatistical Analysis. 2nd ed, Prentice-Hall, Englewood Cliffs

(Received March 9, 2007 / Accepted August 20, 2007) 